\title{
UNA POÉTICA DE LAS ALIANZAS. TENSIONES, CRUCES Y REDES EN LA POESÍA DE BEGOÑA UGALDE ${ }^{1}$
}

\section{A POETICS OF ALLIANCES: TENSIONS, CROSSES, AND NETWORKS IN THE POETRY OF BEGOÑA UGALDE}

\author{
Karem Pinto Carvacho \\ Universidad Autónoma de Chile, Facultad de Educación \\ Ricardo Morales 3369, Santiago, Chile \\ karem.pinto@uautonoma.cl
}

\begin{abstract}
RESUMEN
Este artículo analiza una tríada de textos poéticos que Begoña Ugalde (Chile, 1984) escribe de 2011 a 2018: La Virgen de las antenas (2011), Lunares (2016) y Poemas sobre mi normalidad (2018). Se sostiene que el conjunto de estos textos compone una poética de las alianzas, entendida como un discurso poético-político representativo en términos generacionales de una posición que apuesta por la integración social. Esta poética
\end{abstract}

Este artículo se enmarca en el proyecto Fondecyt 1180331, "Representaciones de la memoria transgeneracional en producciones artístico-culturales de hijos y nietos en países del Cono Sur, 1990-2017”; y del proyecto DIUA 158-2019, "Poesía y memoria: las imágenes del pasado en la producción escritural de las últimas generaciones en Chile (2003-2018)", en conjunto con el trabajo desarrollado en el grupo de investigación Literatura y Escuela de la Universidad Autónoma de Chile. 
se materializa en tres estrategias escriturales: i) la representación de la subjetividad poética desde los ciclos de la vida -la infancia, la juventud y la madurez-; ii) la inscripción de tópicos de conjunto -el santo rosario, el sistema lunar, las constelaciones familiares-; y iii) las imágenes relativas a la comunidad de mujeres -las relaciones madre-hija, hermanas, mujeres-amigas, mujeres-escritoras-artistas-.

Palabras clave: poesía de mujeres, violencia politica, lenguaje poético, alianzas

\section{Abstract}

This article analyzes three poetic texts written by Begoña Ugalde (Chile, 1984) between 2011 and 2018: La Virgen de las antenas (2011), Lunares (2016) and Poemas sobre mi normalidad (2018). It argues that these texts constitute a poetics of alliances, which is understood as a poetic-political discourse that is representative, in generational terms, of a position that is committed to social integration. This poetics is revealed in three literary strategies: 1. The representation of poetic subjectivity in the cycles of life: childhood, youth, and maturity; 2. Recurring topics: the holy rosary, the lunar system, family constellations; and 3. Images relating to women: mother-daughter relationships, sisters, female friends, women-writer-artists.

Keywords: Women's Poetry, Politic Violence, Poetic Language, Alliances 
Te cuento un sueño que se repite: estábamos mirando a nuestros hijos dormir evitando hablar de las ausencias, mordiéndonos las uñas y veíamos cómo todos esos fantasmas se propagaban sobre nuestras cabezas Nos arrodillábamos a los pies de sus pequeñas camas, pegábamos estampitas de santos sobre ellas para protegerlos pero el miedo se encendía en nosotras como una celebración (Begońa Ugalde, La Virgen de las antenas)

La obra de Begoña Ugalde, poeta chilena nacida en 1984, es una producción heterogénea, compuesta por textos que se abren a la experiencia de los géneros poéticos, narrativos y también dramáticos. En particular, su escritura poética se viene armando desde el año $2010^{2}$. Entre esos trabajos me concentro en la lectura de tres de ellos: La Virgen de las antenas, Lunares y Poemas sobre mi normalidad. La hipótesis que me guía es que el proceso de construcción de la voz poética de los textos de Ugalde se ancla en los formatos de la autobiografía y la autoficción, donde ingresa lo colectivo. Lo que se plasma a nivel textual en diversas estrategias discursivas que dibujan a una sujeto que se representa desde la tensión que opera entre las figuras del quiebre y la reconstitución. Expone, por una parte, la fragilidad de su ser interno -constituido por vínculos rotos, miedos, inseguridades y silencios- $y$, por otra, el deseo de reconstitución del yo en una trama de lazos comunitarios imprescindibles (amistades, relaciones, familia, pareja, hijos).

En este sentido, podemos identificar en el trabajo escritural de Ugalde el diseño de una sujeto poética que alude al individuo contemporáneo y la sociedad que habita, expresados en términos de subjetividades a la deriva, marcadas por los múltiples eventos trágicos que definen el fin de siglo XX y el tránsito hacia uno aún más complejo, el XXI. Sujetos/as, en trayecto de múltiples revisiones y reflexiones, permanentes "balances

2 El cielo de los animales (Calle Passy, 2011, Edición virtual, 2010), Thriller (Plup, 2011), La Virgen de las antenas (Cuneta, 2011), Lunares (Pez Espiral, 2016), Poemas sobre mi normalidad (Ril Editores, 2018) y La fiesta vacia (Teje, 2019). 
y retornos" que, a la vez, vuelven "sobre el tiempo cotidiano, el trazado de historias singulares, grupales, generacionales, la afirmación de nuevos mitos fundacionales y políticas de identidad -étnica, religiosas, sexuales, de género, etcétera-” (Arfuch 44). El dilema y la circulación entre el afuera y el adentro, lo público y lo íntimo, lo colectivo y lo personal, el quiebre y la restauración, la melancolía y el duelo, aparecen diáfana y complejamente en las divagaciones poéticas de esta autora.

En términos generacionales, tomando como referencia el quiebre institucional que produjo la dictadura cívico-militar en Chile (1973-1990), Ugalde se encuentra entre la segunda y la tercera camada de poetas chilenas; este no es un dato menor, ya que además, como ella misma seńala, es nieta de un refugiado de la Guerra Civil española ${ }^{3}$. Por tanto, podemos entrever que sus relatos de ascendencia, tanto paterna como materna, se hallan determinados por distantes y cercanas historias de violencia política, que recaen y confluyen inevitablemente en esta escritura posdictatorial, configurada por una voz que se identifica en su discurso poético directamente como hija y nieta; una escritura de lo escindido, enunciada desde la vacilación y el desamparo, desde los silencios y los secretos (Schwab), pero, a la vez, una escritura vinculante, que ensaya puentes entre la precariedad de esas experiencias movedizas, que traza sentidos entre esos itinerarios transgeneracionales y transatlánticos:

Afuera dos policías

fuman y miran sus teléfonos

porque los disparos

los golpes

siguen sucediendo en cada cuadra

pero de todas formas esta noche

las cosas se ven brillantes y limpias.

(Poemas sobre mi normalidad 33, la cursiva es mía)

3 Comunicación personal con la poeta, 5 de febrero, 2019. 
Así, el espacio poético que Ugalde diseña queda imantado por un halo de tragedia, la representación de un espacio que oscila ansiosamente entre el afuera y el adentro, que se mueve fluida, pero que tiene algo de escape, una escritura al borde, en la que parece que lo peor siempre está por suceder, que la cotidianeidad espera amenazante y peligrosa a la vuelta de cada esquina. Sin embargo, a pesar de esa evidente inestabilidad del universo ugaldiano, en esta escritura aparecen indelebles señas que pugnan por la unidad, por el encuentro y la filiación. Y allí se instala de cierta manera el discurso ético y político que tras la debacle del mundo se compromete a su reintegración. Se trata del dibujo a mano alzada y temblorosa de distintos círculos concéntricos, todos los que se encuentran, se intersecan, se interrumpen y se acompañan, dando forma a esta poética de las alianzas. Cada uno de esos espacios insiste en el deseo de encuentro y continuidad, materializados poéticamente mediante distintas estrategias escriturales, entre las que podemos destacar tres:

- La representación de la subjetividad poética desde los ciclos de la vida: la infancia, la juventud y la madurez.

- La inscripción de tópicos de conjunto: el santo rosario, el sistema lunar, las constelaciones familiares.

- Imágenes relativas a la comunidad de mujeres: las relaciones madrehija, hermanas, mujeres-amigas, mujeres-escritoras-artistas.

\section{LA SUbJeTIVIDAd POÉtica Y LOS CIClOS DE LA VIDA: LA INFANCIA, LA JUVENTUD Y LA MADUREZ}

La representación de las etapas de la vida aparece de diversas formas en el conjunto de los textos como un motivo central al que se recurre enfáticamente para delinear el espacio biográfico. Sin embargo, cada poemario se focaliza en una etapa, existe un orden cronológico y se presenta el proceso de la vida en tres tiempos.

La Virgen de las antenas abre con la representación del parto en la casa materna, lo que establece fuertemente el lugar de enunciación de género 
y da inicio a la entrada de la voz de la infancia de la sujeto poética y los recuerdos de una constreñida educación escolar católica. El espacio inicial del nacimiento se carga de los motivos del combate, la incertidumbre, el delirio, la animalidad y la fragilidad de lo estable: "Ya no puede detenerse la tormenta eléctrica” (9), vaticina el poema de la apertura textual, haciendo estallar el contínuum del tiempo, para irradiar el pasado y el futuro que reclaman intensamente presencia y transformación (Benjamin). Este evento se establece como la bisagra que desordena el relato progresivo y permite la imbricación de las experiencias vitales, sucediendo a la vez la pérdida y la recuperación de la infancia, el tránsito angustioso hacia la maternidad y la vida adulta, y con todas ellas la renovación amplia de las existencias. Se trata de un cisma que ilumina un pasado pendiente, inscrito en el presente como posibilidad de empoderamiento, un pasado que se registra en el presente textual mediante el relato autobiográfico del diario de vida. Este tipo textual en clave poética relata la memoria de la nińez y la adolescencia, como períodos asediados por mandatos sociales y religiosos, atravesados por el desacato, el erotismo censurado y el erotismo descubierto, las culpas y las represiones, dice la hablante: "No aprendo los mandamientos, / me saco malas notas en religión, / no me gusta estudiar las parábolas, ni logro colorear dibujos sin salirme del contorno" (La Virgen 26).

Lunares, el segundo texto, da paso a la representación de la juventud: los pequeños viajes, la vida intensa y cotidiana, las emociones, la ciudad y la noche, la casa de paso, los rituales de la celebración, el baile, el descanso, el amor y la pasión, "los paraísos breves" (50), las olas y el mar. El paso del tiempo, como el ciclo de la luna, también es un motivo esencial en este texto, la vida de los sujetos está en constante cambio y añoranza, la pérdida de su juventud queda representada por los movimientos lunares: sujetos vacíos, llenos, creciendo y decreciendo a la vez. Sujetos perdidos y silentes que habitan un espacio urbano hostil, pero que pujan por el "deseo de encuentro" (50):

no es posible cumplir la misma edad dos veces pero sí dar la vida en cada encuentro 
habitar esa ofrenda como un refugio

en medio de la nada (Lunares 51)

Por último, Poemas sobre mi normalidad es un canto a la vida adulta y familiar. Todo pareciera ser un trayecto perfecto desde el espacio público y agitado de los dos textos anteriores para desembarcar en la casa establecida, en el hogar construido. Los poemas se abren desde la incorporación de los padres, los otros, los hijos, la pareja, los amigos, todo ellos en conjunto: la familia, para ir avanzando deseosa y lentamente hasta llegar al deslinde del yo íntimo y su posterior disolución en el pensamiento abstracto sobre las fuerzas que dan movimiento al mundo poético: el amor y la locura. El lazo sanguíneo se poetiza, pero también se corta, se tensa, se rompe y se borra, la voz poética se hace cargo con templanza de la representación de un mundo que no ha dejado de ser amenazante, pero que es enunciado desde la transformación, la reparación y la certeza de los afectos:

La comida está lista, llamamos a los niños

con nombres de animales

es que lo más bello se parece a lo más bello como el mar que toma formas cambiantes con la luz de las estaciones y las mareas. (Poemas sobre mi normalidad 46)

\section{TópICOS DE CONJUNTO: EL SANTO ROSARIO, EL SISTEMA LUNAR Y LAS CONSTELACIONES FAMILIARES}

Los tres poemarios se sostienen en el desarrollo de un motivo central que referencia a la idea de sistema o conjunto, por lo cual, podríamos decir que en la obra de Ugalde la recurrencia de esta idea transforma esos motivos en tópicos. El santo rosario (La Virgen de las antenas), el sistema lunar (Lunares) y las constelaciones familiares (Poemas sobre mi normalidad) son tópicos de conjunto, tanto en forma como en contenido, en el entendido de que cada uno de ellos refiere a la idea de un complejo vivo y creciente, organizado 
por elementos diversos y símiles a la vez, que se precisan interrelacionados para su significación y funcionamiento particular e integral. Se trata, de macroestructuras textuales significativas que, al incorporar y contener las estrategias de igual índole aludidas por el análisis, particularizan -en su resignificación- y actualizan -en su insistencia simbólica y temática- la idea de la articulación y reconstrucción de las comunidades.

El rosario (La Virgen de las antenas) corresponde a un motivo de conjunto en su doble dimensión, pues designa el rezo -compuesto por una serie enlazada y repetida de oraciones de carácter religioso- $y$, materialmente, a la sarta de cuentas unidas por un hilo con la que se practica o se recitan dichas oraciones ${ }^{4}$. Sin embargo, el diálogo intertextual que el discurso poético establece con el discurso religioso es de oposición mediante distintas intervenciones. La más evidente indica que, si bien la composición discursiva del rosario propone la imagen ejemplar de obediencia de una María-madre-mujer-virgen de índole paciente-muda -como personaje secundaria y contemplativa de la experiencia masculina-, en La Virgen de las antenas esa figura o su representación deviene en una protagonista activa y crítica de su diferencia de género; y a través de la exposición de su experiencia personal y pública, problematiza y tensiona su identidad, es decir, mediante la escenificación de las prácticas anuladas, en este caso, por el carácter cristológico del discurso religioso del rosario, focalizado en la difusión de las acción y las enseñanzas del Hijo predilecto del Padre (Carta apostólica).

Otra estrategia que subvierte el texto católico y que denota la insurrección del discurso poético frente al religioso -entendido también como sinécdoque, es decir, como parte representativa del sistema sexo-género- corresponde

El rosario es el rezo católico dirigido a la Virgen María. Está compuesto por "veinte 'misterios' (acontecimientos significativos) de la vida de Jesús y de María, divididos, desde la publicación de la Carta apostólica Rosarium Virginis Mariae, en cuatro 'rosarios"': misterios gozosos, luminosos, dolorosos y gloriosos, en orden. A pesar de que se indica su carácter mariano, está centrado en la figura de Cristo, pues se entiende como un compendio de su mensaje evangélico: "Con él, el pueblo cristiano aprende de María a contemplar la belleza del rostro de Cristo" (Carta apostólica Rosarium Virginis Mariae). 
a la intervención del orden del rosario, ya que la superestructura de $L a$ Virgen de las antenas es inversa, comenzando con los misterios gloriosos, a los que siguen los misterios dolorosos y luego los gozosos, denotando así la desarticulación o deslegitimación absoluta de su norma. En este mismo sentido, podemos observar la ausencia de los misterios luminosos (incluidos por Juan Pablo II, 2002), que no solo son eliminados, sino que además son sustituidos por los inéditos misterios piadosos, eso junto con una serie de otros apartados coherentes o no al relato del rosario ${ }^{5}$, en un gesto que desborda su estructura y amplía el relato experiencial hasta llevarlo a la cotidianidad íntima y familiar de registro femenino; se trata de un ejercicio escritural significativo, ya que en la práctica iguala el rol de la enunciante/ mujer a la del sumo pontífice, en términos de actividad y poder, como gestora de sus propias señas y discurso.

De allí, se entiende que los contenidos de estos misterios religiosos, ya alterados en su orden, sean también intervenidos para ser reescritos en los términos que a la enunciante le hacen sentido respecto de su particular trayecto identitario. En este rumbo y en términos generales, por ejemplo, los misterios gloriosos (que corresponderían a la resurrección de Jesús y la ascensión de la Virgen, de allí la gloria), en el texto poético, abordan el inicio del recorrido autorreflexivo desde un momento trascendental en la experiencia de la enunciante: el parto y nacimiento del propio hijo; los misterios dolorosos (agonía, calvario, crucifixión y muerte del profeta judío) corresponden a la seguida pérdida de la infancia de la sujeto poética y su encuentro angustioso con la maternidad; y de la misma forma, en los misterios gozosos, en lugar del nacimiento y la infancia de Jesús, se expone el proceso de identificación/diferenciación con/de la madre y el descubrimiento del propio cuerpo y el placer erótico. De esa manera, los

Las doce secciones que componen el texto poético son dispuestas en el siguiente orden: I. Misterios gloriosos; II. Misterios dolorosos; III. Semanas santas (diario de infancia); IV. Misterios gozosos (diario de adolescencia); V. Nieve virgen (diario en blanco); VI. Misterios piadosos (diario en tránsito); VII: Paganas escrituras (diario de huida); VIII. Tierra prometida (diario del despojo); IX. Transfiguración (o segundo ascenso al cerro); X. Anunciación de la virgen (diario del Génesis); XI. Los rostros de la virgen (diario de revelaciones); XII. Llamadas de larga distancia (epílogo). 
episodios religiosos son desconstruidos desde el enfoque de género hasta su identificación con un espacio femenino colectivo y plural ("Los rostros de la virgen”) y su bajada al complejo espacio personal de la relación madre-hija ("Llamadas de larga distancia”).

Respecto del sistema lunar en el poemario Lunares, el tópico resulta claro en la inscripción abierta del fenómeno, sus relaciones internas y externas, es decir, afirma la creencia de que los ciclos lunares están imbricados con el curso de la vida humana y el mundo natural y, más allá, asienta el establecimiento de fuerzas continuas, interrelacionadas y armónicas que mueven el cosmos. Desde el mundo poético, el texto instala esas asociaciones y vínculos entre los ritmos del mundo exterior y el interior, entre las fases de la luna (libraciones) y las marcas en el cuerpo (lunares) de manera directa e inmediata desde la apertura en el título del texto. En este sentido, la relación entre el movimiento del universo y los ciclos biológicos se abre para aludir también a la pregunta por el pasado y la identidad como un proceso de reconstrucción oscilatorio, en una mirada macroexistencial que también incluye la contemplación de las vidas pasadas y las herencias familiares: "preguntas por las marcas oscuras que llevo repartidas sobre la piel" (28);

\author{
mis lunares \\ son la piel de quienes fui \\ y de otra que descubre \\ paraísos breves \\ antes que amanezca (Lunares 50)
}

Allí quedan inscritos la pluralidad de las experiencias y el tránsito de las identidades -complejas, contradictorias y móviles- la corporización y su definición de la diferencia sexual.

El texto se organiza en cuatro secciones según el tránsito de la luna menguante, hacia la nueva y la creciente para cerrar con la luna llena; ese transcurso se enfatiza mediante la reiteración de sus imágenes visuales, presentadas en todo el formato de la obra (el calendario lunar en la cubierta, las cuatro fases en la apertura macrotextual y cada una de ellas como 
subtítulos de los cuatro apartados que componen el poemario). A modo de la ruta que los cuerpos transitan en el tiempo, los cambios lunares se coordinan con la sucesión de las imágenes de la vida juvenil, encaminadas hacia su pérdida, anunciando la inminencia de la vida adulta.

Las tres primeras secciones se abren apenas cae la noche: el inicio poético se instala en la urbe nocturna, cuando la luz de la luna comienza a disminuir (luna menguante), anunciando el inicio del decrecimiento. Las imágenes se concentran en el intervalo que se da entre el fin de una jornada laboral y el inicio de la siguiente, en ese espacio de descanso y de silencio, donde el amor se manifiesta profuso y frágil, amenazado por los temores del inconsciente:

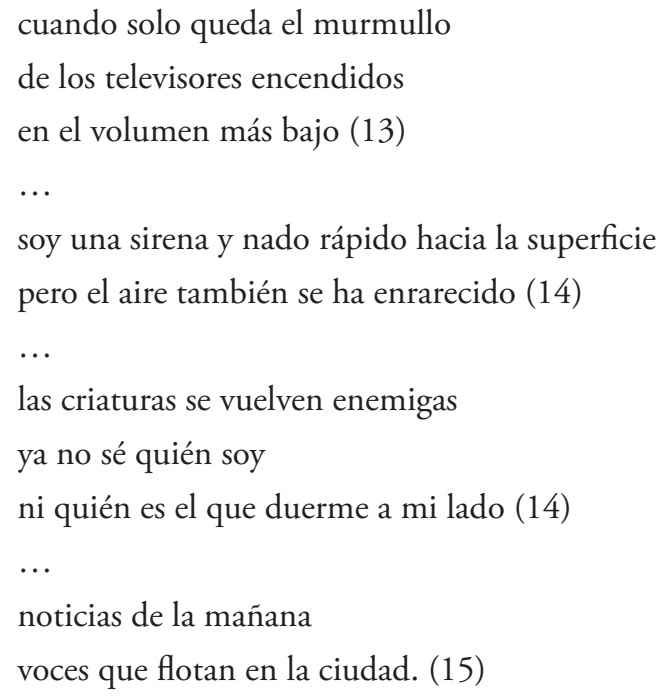

El trayecto de los sujetos continúa hacia el segundo apartado en conexión con la luna nueva y la ineludible escena del océano y sus mareas, pues el saber popular indica que el movimiento de las aguas se relaciona con los cambios lunares; los cuerpos juveniles parecen quedar imantados por esa energía, con todo, en la huida de la ciudad, los signos siguen siendo aciagos: 
tomamos el último bus a la costa (21)

$\cdots$

imaginamos cartas, mapas de navegación

que pronto perderemos para seguir a la deriva (26)

$\cdots$

parecemos cuerpos sin vida

que llegan a la orilla

después de la tormenta (31)

La tercera etapa (luna creciente), refiere una vuelta al espacio urbano y las intensas celebraciones nocturnas que eluden sin perder de vista la tragedia inscrita en la urbe:

en la ciudad hay tantas fiestas

y aunque nadie sabe qué celebramos

me dejo llevar por los augurios de las amigas

...

ignorando el cansancio de la semana,

los golpes que esconde cada esquina. (36)

Lunares cierra con la luna llena y el regreso al cotidiano, la fase final es la única parte que se abre en la ambientación de la madrugada, cuando la luna ya ha alcanzado su plenitud y comienza su anunciada desaparición, el fin de la vida nocturna y así de la juventud; entonces, la intensidad de la urbe se hace más densa y ruidosa, la inclemencia de realidad se cierne amenazante sobre los sujetos:

por las ventanas entran las cenizas

el grito histérico de las bocinas

olores de comidas y diálogos cortados

por una arquitectura que no entiendo (46).

La luna llena, sin luz propia, ha sido perdida "en la claridad día” (45). 
En cuanto al tópico de las constelaciones familiares, podemos apreciar que el clan tiene una presencia marcada, central y extensiva en Poemas sobre mi normalidad. La enunciante afirma una clara conciencia de su árbol genealógico y de la vida en comunidad -ya expresada en sus otros poemarios-. Aquí se presenta como el espacio de reflexión madura sobre el restablecimiento de lazos sanguíneos, en una actitud menos conflictuada y más certera, es decir, que declara un trabajo de memoria elaborada donde surge la reconciliación entre el colectivo y el yo.

La elaboración de estos procesos en el trayecto poético de Ugalde han sido abordados por la psicología en lo que se conoce como la dimensión transgeneracional del trauma, para señalar que los daños ocurridos a una familia o un colectivo más amplio son heredados y sus consecuencias traumáticas son padecidas por los descendientes hasta, por lo menos, las tres generaciones siguientes (Martín-Baró; Cintras). De acuerdo con esto, la interpretación de la transmisión transgeneracional del trauma y la denominada criptonimia que postulan Abraham y Torok, refiere, de manera metafórica, a la tumba intrapsíquica en la que el sujeto traumatizado alberga un duelo irresuelto compuesto de dolores, silencios y secretos de los que no logra, no puede, desprenderse. Ese trauma viajaría hasta las generaciones posteriores, adoptando características particulares en cada una de ellas, de manera que en la generación inmediata sus contenidos serían innombrables, en la siguiente generación compuesta por los hijos/as, indecibles; y, finalmente, en la tercera generación de nietos/as, impensables, por lo tanto, su desciframiento respecto del trauma originario se vería impedido o profundamente limitado. A pesar de ello, estos contenidos traumáticos pueden ser observados en el discurso a través de múltiples formas, ya sea distorsionadas, figurizadas o imperceptibles. En los textos de Ugalde, las marcas de este proceso aparecen en diversos lugares, en el tono ansioso y la sensación de melancolía permanente que recorren sus escritos, cuyo origen no es claro, pero que parecen estar inscritos sordamente en el cotidiano. Al respecto, la cita que abre este artículo es rotunda, sin embargo, hay una seguidilla de alertas que se suceden como flashes, apuntando hacia el indeterminado lugar de la catástrofe, inscrita en diversas imágenes: el 
pesebre fragmentado, una enunciante encandilada recorriendo las calles y la historia de Chile, el olor a pólvora, los estallidos, los campanazos que suenan con persistencia, la seña de criminales y violadores, el silencio que los ronda, las múltiples figuras fantasmales que aparecen y desaparecen:

Lo distinguí como un espectro

entre los espectros indiferente al calor

tan pálido, sin miedo, parecía

regresar pero no entender

los adornos, los días festivos. (59)

En Lunares, siguen sucediendo, en la mención a los golpes, accidentes y el cansancio, las pérdidas, lo indecible y lo impensable:

quiero que entres en mí

como si fueras a contarme un secreto

-

como si hubieras llegado a este lugar

después de una larga enfermedad (40)

las cosas más importantes que nos pasan

son un reino de silencio

la sílaba que no sabemos pronunciar (52)

En este sentido, en Poemas sobre mi normalidad, la enunciante ha llegado a desentrañar el espacio íntimo desde la comprensión de su individualidad vinculada al colectivo, dando a cada uno de los integrantes del clan su justo espacio, de allí que el trayecto de sanación empieza a ser definido. Así, el mapa afectivo queda diseñado como un lugar de armonía, pero no de una falsa armonía, porque consiente y no elude sus complejidades. Entonces, la casa de los ancestros no deja de ser portadora de secretos, las carencias cotidianas, emotivas y materiales, interrumpen y los golpes, los muertos y los fantasmas siguen presentes. A pesar de eso, el estado melancólico está incorporado 
suavemente, lo que permite apreciar que los rostros de los padres "están muy cerca el uno del otro" ("Mis padres no son intelectuales" 15), ambos entregando lecciones de libertad, compromiso y resistencia ("Lección", "Carta”, "Pájaros que soportan el invierno"), que la abuela es una figura definitoria de la identidad personal (“Cenizas al mar”), que la hermana es símbolo de emancipación y espiritualidad, y que la familia central es lo más cercano a la simple felicidad: "es que lo más bello se parece a lo más bello / como el mar que toma formas cambiantes / con la luz de las estaciones y la mareas" (46). Esto, es lo que permite ampliar este colectivo hasta integrar a los desconocidos sufrientes de la humanidad: animales asesinados y suicidas, entre otros.

El texto, al igual que los otros poemarios, está dividido en cuatro apartados ("Lazo sanguíneo", "Tesoros escondidos", "Pequeños milagros" y "Apuntes sobre el amor y la locura”), sin embargo, a diferencia de ellos la superestructura queda más abierta y los temas y motivos, aunque definidos en cada uno de ellos -los progenitores, los otros/as, la familia nuclear, la reflexión personal, en orden de aparición-, pasan fluidamente de una sección a las otras, como si las redes se hicieran extensivas entre sí. Así, la jerarquía y el orden se deshacen, para dar paso a un campo estelar reconocido, que avanza hacia y permite la autonomía, allí donde el espacio se define entre el amor y la locura, y donde la muerte ya no es determinante.

\section{Comunidades de mujeres: MAdRe-hiJA, hermanas, MUJERES-AMIGAS, MUJERES-CREADORAS}

En estos poemarios existe una posición de género decidida y declarada expuesta en términos de sororidad. En La Virgen de las antenas el enfoque genérico se dibuja con mayor fuerza. La figura de la Virgen del Cerro sirve de motivo a todo el cuestionamiento de los mandatos patriarcales y la anulación del mundo de las mujeres, que el texto hace emerger en todas sus dificultades, "No hay / Madre virgen / No." (81), manifiesta su desacato. Se establece una grave identificación entre la figura de la Virgen y la madre terrenal, en un espacio que las presenta como seres imponentes, distantes, 
imposibles para una hija que se busca a tientas entre ellas, que pide ayuda, protección y escucha, pero que recibe cuestionamientos y silencios de una gran mole ausente. La simbólica de la Virgen, también, permite la aparición, por contraste, de otras Marías, Marías hermanas, las Marías de Chile, una gama de mujeres reales, distintas e insurrectas ${ }^{6}$. Por lo tanto, hay aquí la tensión entre la experiencia de dos generaciones representadas en la madre y la hija, el encierro de una y la libertad de la otra, el silencio de una y la palabra de la otra; pero también hay la conciencia del linaje, del vínculo y el compromiso entre ambas generaciones, encuentro representado en el traspaso de los conocimientos relativos a la medicina natural, la cultura popular y en el retorno del goce sexual en nombre de la madre-virgen enclaustrada. "Se trata de devolverle la vida a esa madre, a nuestra madre en nosotras, y entre nosotras. De darle derecho al placer, al goce, a la pasión. De darle el derecho a las palabras y, por qué no, a veces a los gritos, a la cólera”, son las palabras de Luce Irigaray (41), que calzan de manera perfecta con las imágenes que reúnen a madre e hija en paso angustioso. De allí deviene el vínculo sororo que salta desde el plano privado al reconocimiento de ese lazo multiplicado en el espacio social, en el encuentro de las experiencias de género y la necesidad del quiebre y la huida para salvar a las/os hijas/os:

Descalza y vestida con sábanas blancas

recorro las calles donde peregriné encandilada

para recolectar páginas sueltas

de la más común de las historias de Chile. (52)

$6 \quad$ Al respecto Alicia Salomone, en su reseña del texto, señala que "Así, el libro nos presenta a una figura femenina que también es una mater pero que, a diferencia de la modélica, ya no queda fijada en esa única posición ni misión, ni en el padecer que ambas conllevan, sino que oscila entre el dolor y el gozo, entre la luminosidad y la degradación, entre el afuera y el adentro, entre la hiperactividad y la introspección autorreflexiva. Como si la hablante, en sus evoluciones, terminara por asumir como propio un lugar de tensión productiva, donde se oponen dinámicamente la aceptación y la crítica respecto del rol femenino preponderante; lo que, al mismo tiempo, la habilita para explorar en nuevas formas del ser mujer" (139). 
Lunares está escrito, como dice el texto, "para mis amigas". Lunares como las marcas en la piel de las vidas pasadas, presentes y en tránsito, pero también en referencia a la Luna, símbolo por excelencia de lo femenino, que viene delineándose así desde las más antiguas civilizaciones y sus mitologías: Coyolxauhqui, la diosa de la luna entre los aztecas, hija además de la diosa de la Tierra, Coatlicue; Artemisa, su símil griego, diosa de la luna y la caza, la protectora de las embarazadas y parturientas. La continuidad entre los motivos del poemario anterior y este se encuentra en la relación entre la luna y la figura de la Virgen. La luna aparece permanentemente retratada en la iconografía cristiana, dibujada a "los pies de la Virgen, como símbolo de pureza" (Inmaculada Concepción de Murillo). "Murillo pintó a la Inmaculada en varias ocasiones, a veces con la luna llena y otras en creciente"; Jan van Eyck la pintó en La Crucifixión, considerada "la primera representación realista de la Luna en el arte occidental” (González Hughet). Asimismo, en los rituales paganos, por ejemplo, aparece en el arcano II del tarot acompañando a la sacerdotisa en representación de lo divino-femenino, la reveladora de los secretos y la poseedora de la sabiduría, además en la carta del inconsciente, el pasado y lo oculto, el arcano XVIII.

La ginecología natural reconoce la influencia de la luna en los ciclos y cambios corporales de las mujeres, los 28 días del ciclo menstrual son el correlato de los 28 días del ciclo lunar, el texto poético alude a ese vínculo general, el que puede ser leído también en la representación de la diferencia sexual femenina: "arriba las constelaciones resplandecen / como la saliva en los labios" (31). La luna aparece en directa relación con el flujo de la vida personal, como símbolo del azar, lo desconocido, lo ambiguo: "miro los hongos del techo / como si fueran constelaciones nuevas / a las que pido señales sobre mi destino" (50); los designios lunares precipitándose sobre un espacio de seńas difusas, nubladas, desconcertantes, donde las amigas, brujas danzantes, recrean y celebran salvajemente los antiguos rituales castigados con fuego. Son mujeres 
que pintan sus ojos felinamente

y se ríen fuerte de los perros

que ladran al sentirnos pasar (36)

$\cdots$

borrosas, con los ojos rojos

contándonos secretos. (37)

En Poemas sobre mi normalidad, las mujeres vuelven a presentarse, pero ahora en escenas de una vida cotidiana más quieta y establecida, "lejos de las habitaciones de la infancia”, ellas se asientan en la protección de la madre ("Lección", "Complicidad"), la muerte de la abuela ("Cenizas al mar"), la visita y las conversaciones con la hermana ("Mi literatura”). Se trata de una red de mujeres con las que se construye -como si de un juego de espejos se tratara- el cotidiano y la vida profunda; son imágenes cercanas, menos temblorosas que en los textos anteriores, signadas por los motivos de los sueños, el crecimiento, los geranios, las cartas amorosas, la preocupación por la otra, el ansia de sabiduría y espiritualidad; son imágenes reconciliadas con los laberintos de las relaciones filiales. Aquí la madre ya no se escapa o aparece como una voz lejana (La virgen de las antenas), ahora es ella la que llama y abre con su voz los sonidos de un día silencioso:

No tenemos suficiente entusiasmo para hacernos visitas

pero a través del teléfono comentamos nuestros problemas

domésticos

reemplazamos los secretos por temas cotidianos

que son para nosotras lo más parecido a la complicidad. (29)

Esta escenificación de una comunidad de mujeres también se da en un nivel formal-semántico, ligado a la estructura dialógica inter y extratextual, es decir, se relaciona tanto con la reconstrucción de las genealogías y las redes de creación intelectual y artística femeninas, como con la legitimación de un universo escritural-experiencial de mujeres. Allí podemos identificar el lazo que la voz autoral establece de manera exclusiva con otras creadoras, 
poetas y artistas, entre ellas Gabriela Mistral, Inger Christensen, Sylvia Plath, Marianne Faithfull y Patti Smith, figuras que Ugalde inscribe de manera directa $^{7}$. Estos diálogos se vuelven una constante en sus textos, pues de manera coral sus voces hacen eco en unos y otros escritos, particularizándose en un vínculo específico con una de ellas en cada texto.

Por ejemplo, el epígrafe que abre Lunares corresponde a una parte del texto poético Alfabeto, de Christensen ${ }^{8}$, y se dirige a la idea de la construcción del universo a través del lenguaje, de la mirada de la poeta que va creando y recreando el mundo apenas es percibido y tocado mediante la imaginación poética ("los albaricoqueros existen, los albaricoqueros existen", 9; "los helechos existen; y zarzamoras, zarzamoras y bromo existen; y el hidrógeno, el hidrógeno", 11). Siguiendo ese sentido, el texto de Ugalde se sostiene sobre la relación que abre el trabajo de Christensen: "sobre el mesón de la cocina / las hormigas dibujan un alfabeto móvil / describen la economía doméstica” (15). De tal manera, el imaginario del paratexto establece un diálogo armónico con Lunares y su trama sobre la continuidad, el movimiento y el crecimiento plural del cosmos, el paso del tiempo y la transformación de los astros y los seres, con todo lo amable y conflictivo que implica.

Por su parte, Poemas sobre mi normalidad, privilegia la voz guía de Sylvia Plath ${ }^{9}$ que se refiere al deseo de la polifonía textual de corte bajtniano, desplegando más allá de la pluralidad de caracteres y personajes, un mundo

7 En este círculo, también se integran obras y escritoras que no son enunciadas, pero con las que los textos arman su red intertextual femenina. Por ejemplo, como señala Salomone, La Virgen de las antenas dialoga, además, con una larga tradición de autoras y textos que han tematizado la figura de la virgen, como Julia Kristeva ("Stabat Mater", 1983) y, en poesía chilena, Eugenia Brito (Vía Pública, 1984, Filiaciones, 1986), entre otras. Estos vínculos que amplían el campo textual convocado, dan cuenta de las memorias intergeneracionales y transgeneracionales que organizan el campo de la escritura de mujeres mediante transmisiones y rupturas.

8 "Habla ahora de dulzura, habla ahora del misterio / de la sal, habla ahora de mediación, seres humanos, / valentía, cuéntame que el mármol de los bancos / se puede comer, cuéntame que la luna es hermosa”.

9 El epígrafe dice "Me gustaría ser todo el mundo. Un tullido, un hombre agónico, una puta, y luego volver sobre mis pensamientos, mis emociones, metida en la piel de esa persona. Pero no soy omnisciente. Tengo que vivir mi vida, es la única que tendré". 
comprendido por la diversidad discursiva y el cruce de voces autónomas que conforman el universo poético, independiente de la voz autoral. El epígrafe anuncia ese enfoque en forma de anhelo ("Me gustaría ser todo el mundo"), pues el entramado dialógico -la composición social del discurso poético- apela a la identificación de la voz personal de la enunciante, o perspectiva autobiográfica, ("Pero no soy omnisciente. Tengo que vivir mi vida”, en tanto que establece necesariamente su distancia del colectivo y reclama con la misma fuerza la definición de su identidad.

Sin embargo, La virgen de las antenas es el texto donde se construye un diálogo intertextual más prolífico, ya que el vis a vis con Mistral no solo ocurre con el epígrafe inicial, sino que se sostiene en extenso, encabezando nueve de doce secciones -con excepción de la IV, que lleva el epígrafe de Plath, la VII, de Faithfull, y la sección XII, Epilogo, que no lleva epígrafe-. Estos paratextos corresponden a versos mistralianos (entre los más famosos, "La cabalgata", "Nocturno de la consumación" y "La fuga" de Tala, 1938; "Noche", "Pinos de navidad" y "Madre mía" de Lagar, 1954), seleccionados por el vínculo ineludible y complejo con la madre (la madre-poeta, la madre-biológica y la madre-simbólica), un tópico fundamental en los textos poéticos, ensayos y prosa de la nobel chilena.

En tal sentido, Ugalde sustenta el enfoque mistraliano que enjuicia la prescripción de la sagrada familia burguesa (Rojo), pues al virar hacia el espacio protagónico de la madre, establece un vínculo representativo con su experiencia y, de ese modo, desplaza el inamovible lugar del hijo para hacer aparecer en escena central a la hija (también hijo-hija, animal-humano en el caso Mistral, por ejemplo, en el Poema de Chile), con lo que la voz poética construye su crítica al discurso religioso y androcéntrico en la construcción del orden establecido (Pinto).

Ambos discursos poéticos, el de Mistral y el de Ugalde, se encuentran, además, en ese tono ansioso que relata la travesía de las relaciones identitarias entre madre e hija, de ternura y reproche, que avanza y se detiene, se descubre y se vela, se compromete y se desvincula. Sin embargo, el discurso de Ugalde se establece desde un lugar generacional distinto, caracterizado por una voz poética más fresca e infantil que sirve a la recuperación de los espacios de 
la infancia a través de los trabajos de la memoria, y que, evidentemente, está interesado en su inscripción en los discursos feministas actuales y su crítica directa al lugar designado a las mujeres en el sistema sexo-género ${ }^{10}$. En este sentido, los textos de Ugalde van más allá de la ansiedad de la poesía mistraliana para establecer una relación más diáfana con las paridades femeninas ${ }^{11}$, o lo que Adrianne Rich denominó el continuo lesbiano para aludir a la histórica presencia lesbiana, que invoca nuestra conciencia sobre "una gama -a lo largo de la vida de cada mujer y a lo largo de la historia- de experiencias identificadas con mujeres" (5). Experiencias lesbianas, más allá de su único contenido sexual-amoroso, entendidas como alianzas, llenas de vida y poder, compuestas exclusivamente por y para las mujeres, y que Rich explica de la siguiente forma:

Si lo ampliamos para que comprenda muchas más formas de intensidad primaria entre mujeres, inclusive el compartir una vida interior rica, el unirse contra la tiranía masculina, el dar y recibir apoyo práctico y político; si también podemos verlo en asociaciones como resistencia al matrimonio y en la conducta "montaraz" identificada por Mary Daly (significados obsoletos: "intratable", "voluntariosa", "libertina" y "no casta" [...] "una mujer renuente a rendirse al galanteo", empezaremos a aprehender dimensiones de la historia de las mujeres y de la psicología femenina inaccesibles hasta hoy a consecuencia de las definiciones limitadas, mayormente clínicas, de lesbianismo. (23)

En este sentido, el trabajo de Ugalde diseña las coordenadas de un espacio en el que las mujeres van en camino de reconocimiento y encuentro

10 Como es sabido la escritura mistraliana se hizo de una voz poética más bien madura y masculinizada, la voz de la vieja sabia, ya que el objetivo principal fue su acreditación para la inserción en el entramado público y literario patriarcal (Rojo; Doll).

11 En la poesía de Mistral aparece la voz y la figuración de un colectivo femenino que no puede ser desconocido como antecedente de la representación de la experiencia de las mujeres ("Locas mujeres" y "Todas íbamos a ser reinas", entre otros textos), pero la distancia está dada, evidentemente, por la actual apertura de los estudios de género y el pensamiento feminista, que provee de tonos menos angustiosos a la poesía de las generaciones actuales. 
identitario a través del continuo lesbiano que toda mujer ha habitado, que toda mujer habita.

\section{Conclusión}

Se puede observar que la construcción de la voz poética en los textos de Ugalde tiene un fuerte componente biográfico - personal y colectivo- que se inscribe tensionadamente entre las figuras del quiebre y la reconstitución. Así la escritura poética nos presenta no solo una voz, sino también la presencia de sujetos/as descentrados/as construidos/as particularmente a través de una razón dialógica, pensada desde sus otras/os incardinados/as, que reposiciona las presencias excluidas y castigadas, escenificando cuadros vivos y vivificantes.

Las estrategias discursivas de los poemarios están diseñadas en torno a los fragmentos (personas, figuras, episodios, escenas, emociones, etapas, tramas, etcétera) que insistentemente arman y tienden a la idea de conjunto, se trata de representaciones, que desde el lenguaje poético podemos denominar como figuras metonímicas; pero que más que trozos abandonados, dan unidad y consistencia a los relatos de la construcción individual y colectiva. Se trata de trozos, más pequeños o más grandes, pero trozos al fin y al cabo, que dan cuenta de la experiencia fragmentaria del mundo, pero también de su autonomía y su articulación, que apuestan constantemente por su reintegración, es decir, que pugnan por la instalación de un sujeto social que de distintas formas intenta, ensaya, pulsa por la reconstitución de los lazos comunitarios. Se trata de un discurso político que tanto en su forma como en su contenido, sus unidades y sistemas, piensa y sostiene esta poética de las alianzas, en una decidida oposición al salvaje contexto contemporáneo neoliberal legado, en nuestro caso, por la dictadura cívico-militar. 


\section{Bibliografía}

Abraham, Nicolás y María Torok. La corteza y el núcleo. Buenos Aires: Amorrortu, 2005.

Arfuch, Leonor. Critica cultural entre política y poética. Buenos Aires: FCE, 2008.

Bajtin, Mijael. Problemas de la poética de Dostoievski. México: FCE, 2012.

Benjamin, Walter. Tesis sobre la historia y otros fragmentos. Bolívar Echeverría, 2005, www.bolivare.unam.mx.

Carta apostólica Rosarium Virginis Mariae del Sumo Pontifice Juan Pablo II al episcopado, al clero y a los fieles sobre el Santo Rosario. Santa Sede, www. vatican.va.

CINTRAS. Daño transgeneracional. Consecuencias de la represión política en el Cono Sur. Santiago: LOM, 2009.

Doll, Darcie. "Las cartas de amor de Gabriela Mistral o el discurso amoroso de una sujeto en fuga". Revista Signos, vol. 33, n. ${ }^{\circ}$ 47, 2000.

Irigaray, Luce. "El cuerpo a cuerpo con la madre". Debate Feminista, 1994, www. debatefeminista.pueg.unam.mx.

González Hughet, Carmen. "La Luna en el arte y en la literatura”. Tu Espacio, www. tuespacioujmd.com.

Martín-Baró, Ignacio. "La violencia política y la guerra como causas del trauma psicosocial en el Salvador". Psicología social de la guerra: trauma y terapia. Selección de Ignacio Martín-Baró. San Salvador: Universidad Centroamericana, 1990.

Pinto Carvacho, Karem. La nación a dos voces Poema de Chile de Gabriela Mistral y La Bandera de Chile de Elvira Hernández. Tesis de maestría, Universidad de Chile, 2008.

Rich, Adrianne. "Heterosexualidad obligatoria y la existencia lesbiana". DUODA Revista d'Estudis Feministes, n. ${ }^{\circ}$ 10, 1996.

Rojo, Grínor. Dirán que está en la gloria... (Mistral). Santiago, Chile: FCE, 1997.

Salomone, Alicia. "Identidad femenina, memoria y (re)creación de sí, en La Virgen de las antenas de Begońa Ugalde". Revista Chilena de Literatura, n. ${ }^{\circ}$ 81, 2012, pp. 137-144. 
Schwab, Gabrielle. "Escribir contra la memoria y el olvido". Estudios sobre la memoria: perspectivas actuales. Editado por Silvina Mandolessi y Maximiliano Alonso. Villa María: Eduvim, 2015.

Ugalde, Begoña. La Virgen de las antenas. Santiago: Cuneta, 2011.

_. $\quad$ Lunares. Santiago: Libros del Pez espiral, 2016

_. Poemas sobre mi normalidad. Santiago: RIL editores. Aérea/Carménère, 2018. 